Column: Innovation in Libraries

\title{
A Sustainable Way Forward: A Team-Based Approach to Tackling Textbook Access and Affordability Issues During the "New Normal"
}

Michelle Brailey, University of Alberta Library

Sonya Betz, University of Alberta Library

\begin{abstract}
Like all institutions across North America, The University of Alberta Library has experienced dramatic impacts on our services and collections due to the COVID-19 pandemic. Students at our large research institution have historically relied heavily on the Library's extensive reserve collection of textbooks and other required course materials, the lending of which was suddenly suspended during a mid-term emergency closure. This column will highlight our team-based approach to aggressively promoting OER to our campus community: from engaging public service desk staff in new roles as their work suddenly shifted, strategizing with our collections team on identifying high impact courses, and establishing a communications approach with librarians. We will discuss how our "by-the-seat-of-our-pants" initial approach has evolved into a functional team with a diverse set of strengths, and a responsive workflow that incorporates OER services as an integrated component of existing library processes.
\end{abstract}

\section{KEYWORDS}

Textbook affordability, open education, course materials, quality education

\section{SUGGESTED CITATION}

Brailey, M., \& Betz, S. (2022). A sustainable way forward: A team-based approach to tackling textbook access and affordability issues during the "new normal." Journal of New Librarianship, 7(1), 80-87. https://doi.org/10.33011/newlibs/11/9

This is an Open Access article distributed under the terms of the Creative Commons Attribution 4.0 International License (http://creativecommons.org/licenses/by/4.0), which permits unrestricted use, distribution, and reproduction in any medium, provided the original work is properly cited. 
Writing a column "On Innovation in Libraries" regarding service changes during the course of a global pandemic certainly runs the risk of reinforcing a narrative that positions a crisis as an opportunity. While it's tempting to look for positive stories during difficult circumstances, we would like to emphasize that while our experience of COVID-19 certainly highlighted ways our institution could make changes for the better, it's important to recognize that this pandemic served to acutely highlight some very deep issues ingrained in libraries' relationships with textbook publishers, as well as systemic issues regarding affordability of educational materials.

Open educational resources (OER) are "teaching, learning, and research resources that are free of cost and access barriers, and which also carry legal permission for open use" (SPARC, n.d.-b, para. 6). Open Education (OE) provides opportunities for educators to develop and share materials for teaching and learning, as well as very important cost savings to students who are often required to purchase expensive textbooks.

Like many post-secondary institutions, in early 2020 the University of Alberta (UofA) offered a range of services and resources dedicated to supporting OE and affordable textbook activities on our campus. We had recently launched a local Open Textbook publishing program for our campus community (University of Alberta Library, n.d), and were working closely with a grassroots provincial group, Open Education Alberta (n.d.) to provide Pressbooks hosting services for other institutions in the province who were growing their own campus OE programs. Our program operated like many other similar programs: We had a librarian with assigned responsibilities to support and promote OER activities on campus, who liaised with other campus stakeholders like the UofA's Centre for Teaching and Learning, the Students' Union, and Bookstore. Uptake of the program was slow, and we faced many of the common challenges to similar programs such as lack of awareness of available services on campus and no shared and consistent approach among stakeholders.

Alongside our OER program, the Library also maintained a course textbook purchasing program, and in partnership with our campus Bookstore, ordered print copies of high-demand textbooks each semester to place on short-term, 2-hour loans, ensuring that students in those courses were able to access many of the required materials for their courses. This program was well received, and students have gained access to thousands of course readings, resulting in 133,844 checkouts since we began operating it in 2015 .

When COVID-19 arrived in Alberta in mid-March 2020, it had dramatic impacts on staff and student access to Library services and collections. The institution moved quickly to emergency remote teaching online, and the Library closed in-person access to our spaces and collections, cutting off access to print material, including our textbook lending program. Very suddenly, and in the middle of a term, students who relied heavily on the Library's extensive collection of print textbooks and other required course materials were no longer able to access 
these items. When we began offering a curbside lending program for access to our material collections, handling policies that required quarantine waiting periods for physical materials meant that short term loans were off the menu. At the same time as we were experiencing this sudden and urgent need for online access to required course textbooks, we were also grappling with restrictive purchasing models from many of the large commercial textbook publishers. Despite a willingness to acquire ebook versions of the textbooks needed by students, most course textbooks are unavailable for libraries to purchase in electronic format (University of Alberta Library, 2020).

The pandemic very rapidly exposed deep and systemic issues, not only the welldocumented textbook affordability issues driving much OE advocacy work (BCcampus, n.d.; SPARC, n.d.-b; Yano \& Myers 2019), but also the growing gap between libraries whose users need online access to textbooks, and publishers unwilling to sell econtent to libraries.

In response to the changes on our campus due to Covid-19, we focused first on addressing the immediate needs of our new virtual work and learning environments. We knew that OE offered a solution to the barriers to access posed by both online teaching and limited access to physical resources from the library collection or Bookstore. Research tells us that a major barrier for faculty in integrating OER into their courses includes finding OER, as well as the time involved to assess and understand OER quality (Goodsett et al., 2016). To help address this barrier, we brought together a team of individuals interested in OE from across the Library, Centre for Teaching and Learning, and Copyright Office to talk about how we could help faculty find high quality OER for their courses with minimal effort and time.

\section{Staffing and Training for a New Service}

Alongside the Library's in-person closure, our Information Services Specialists (ISS), who provide face-to-face reference and research assistance at our public service desks, suddenly found themselves working from home, supporting students and faculty through virtual services instead. We turned to these experts in searching library catalogues and databases as natural partners in developing strong in-Library expertise for locating high quality OER for faculty. The Digital Initiatives Librarian, with responsibility for our OE program, recruited four ISS staff to form a small OER search team to respond to requests for finding OE materials.

Our ISS staff were new to OE, so we developed some local training materials for the team based on existing openly licensed resources from the SPARC OER Leadership program curriculum, which provided an excellent background to OE basics as well as useful search strategies for locating OER (SPARC, n.d.-c). We also modified the SPARC OER Treasure Hunt to use as a template guide for searching for OER, and we've continued using this template with every search request (SPARC, n.d.-a). Modifying these existing high-quality resources allowed us to proceed with our work very quickly and provided staff with excellent information. 


\section{Shifting Focus}

As the first few months of the pandemic unfolded, it became apparent that this mode of teaching and learning was the "new normal" and that we needed to shift our approach to more actively and effectively promote OER adoption on campus. In considering where to focus our efforts, we decided to try to proactively target introductory-level courses with high enrollment and expensive textbooks. From our experience searching for OER, we knew that courses such as first year social sciences, math, and sciences would be likely to have high quality, comprehensive OER available that would require minimal adaptation for faculty. We were also well aware that some textbooks are much more expensive than others, and encouraging faculty to replace those titles with an open alternative would have the greatest impact on affordability for the largest number of students. To locate appropriate courses, we browsed both the University's calendar of courses and the University Bookstore's textbook lists for previous terms, under the assumption that textbook selection tends to remain fairly stable year after year for many courses. We narrowed our very large lists of available courses by the number of students enrolled, the course level, textbooks being taught, and the costs of the textbooks. With a list of potential courses and textbook titles in hand, the search team matched courses at the University of Alberta with existing OER options. In total the team has searched for appropriate OER to match over 130 courses at the University of Alberta.

While front-line staff searched for OER to match existing introductory level courses, we worked with the University of Alberta's subject librarians to develop an approach for communicating and building awareness with their faculty and departments about the work underway at the library. To introduce the subject librarians to the project, and allow for time for everyone to ask questions and understand the goals of the work, we scheduled a series of dropin virtual sessions with small groups and one-on-one meetings available. Since each academic department and faculty have their own unique culture, and varying levels of familiarity with and enthusiasm for OE, we felt that a flexible approach would have the most success. We asked subject librarians to help us share information with their departments in whatever way they felt would be most successful. To help ensure consistent messaging and to save their time, we drafted a scripted message that they could adapt and share as needed (see Appendix A). We took a pragmatic approach in our communication efforts, and presented OER alongside other online options for no-cost and low-cost student textbooks, including licensed ebooks we already had in our collection and options for the library to purchase new titles with suitable access models. Though OER was a key message, and we certainly perceived OER as one solution to many of the access and cost issues our students were facing, we were also mindful that there aren't appropriate OER available for many areas of study, and our rich and varied collections already offered suitable no-cost (if not openly licensed) options for faulty that they could use as an alternative to having their students purchase an expensive required textbook. 
The final shape of the program is quite different from where we began. We now have a well-trained, expert OER search team who can effectively field direct requests from instructors who wish to replace a traditional textbook with an openly licensed or no-cost alternative. This team has also identified and documented dozens of potential replacement titles for large introductory courses with expensive required textbooks. Our subject librarians are well versed in the nature of this program, and are able to direct requests and guide conversations to OER as needed, and are comfortable referring requests as awareness grows on campus.

\section{Reflections}

Reflecting on our service development during this tumultuous time, there are several areas that we believe were key to our success, as well as gaps in our service delivery that we look forward to improving on in the future.

\section{Collaboration is Key}

Our experience developing an OE program has illustrated that collaborative practices for building and maintaining services are critical for the development and communication of OE work. In addition to the Information Services Specialists who carried out so much of the labor of this program, other key stakeholders advising on direction and development included our Centre for Teaching and Learning, Students' Union, Bookstore, Copyright Office, and subject librarians who all brought and continue to bring unique perspectives. Each group offers important knowledge about the core messages needed to reach every group on our large, diverse campus. For example, the OE needs of an Engineering class might be very different from the considerations of a course in the Social Sciences or Humanities. Students also have different needs and wants for suitable resources than faculty. Overall, utilizing these collaborative and reflexive practices were important to the development of our OE service.

\section{Every Institution is Unique}

The Covid-19 pandemic has required us to urgently reimagine our Library's relationship to providing access to course materials like textbooks. Library public service desk staff have extensive training and experience searching for diverse materials. At our campus, searching for OER was a natural fit with these existing skills, while also allowing staff to engage with this new and important project as work from home orders required us to change in-person service roles. Overall, this allowed us to think about OER as integrated with staff roles in a way that was not radically new.

While this approach has been successful for us so far, it is important to note that each institution has a unique community and their own considerations for what will make an impactful library approach to OE. Taking the time to both understand the unique circumstances of our institution and move forward appropriately was key.

\section{Evaluating Success}


One shortcoming of our approach is that we didn't build in any mechanism for feedback aside from incidental reports of OER adoption or messages of thanks from faculty. Because the project team was one step removed from the communications activities of the subject librarians, we relied heavily on their feedback and perceptions of how the messaging was being received by departments and faculties. For courses where we responded directly to search requests for OER from faculty, we didn't include a follow-up step to learn if they indeed ended up using the resources we located for them, or how satisfied or dissatisfied they were with the titles. It was only anecdotally that we later learned of the use of OER content that we found in courses. This is certainly an area we can improve on in the future.

\section{Conclusions}

Although our current approach to OER services was directed by necessity, the OER search program has grown into a sustainable and ongoing service that works together with our publishing program to more solidly support a range of OER implementation and outreach within our library system. As of Spring 2021, we have continued to offer searching for OER as an operationalized service with four staff members trained to respond to requests. Formalizing and building on our OER efforts into the future required a more strategic approach, so in February of 2021, we also launched a dedicated OER Team to coordinate efforts with a variety of stakeholder groups within and outside of the Library. We understand from Smith and Lee (2017) that building community around OE practices is an effective strategy for moving OER initiatives forward. We hope the new OER Team's membership of subject librarians, faculty, students, the Copyright Office, and the Centre for Teaching and Learning will continue to build our program by engaging these many stakeholders towards common goals beyond information sharing, and towards operationalizing collaborations to strengthen services and support OER adoption across campus. 


\section{References}

BCcampus. (n.d.). Advocating for open education. https://open.bccampus.ca/advocate-foropen-education/advocating-for-open-education/

Goodsett, M., Loomis, B., \& Miles, M. (2016). Leading campus OER initiatives through libraryfaculty collaboration. College \& Undergraduate Libraries, 23(3), 335342. https://dx.doi.org/10.1080/10691316.2016.1206328

Open Education Alberta. (n.d.). Library publishing for open textbooks. https://openeducationalberta.ca/

SPARC. (n.d.-a). OER treasure hunt worksheet | Version 1.o. https://docs.google.com/document/d/14djA9Rl9YOfOvfE3m1Wgk8HnETytKc9k4kgK7 z7t hU/edit

SPARC. (n.d.-b). Open Education. https://sparcopen.org/open-education/

SPARC. (n.d.-c). Open Education Leadership Program curriculum. https://sparcopen.org/ourwork/open-education-leadership-program/curriculum/

Smith, B., \& Lee, L. (2017). Librarians and OER: Cultivating a community of practice to be more effective advocates. Journal of Library \& Information Services in Distance Learning, 11(1-2), 106-122. https://doi.org/10.1080/1533290X.2016.1226592

University of Alberta Library. (n.d.). Publishing at the University of Alberta Library. https://library.ualberta.ca/publishing/

University of Alberta Library. (2020, August). Commercial eTextbooks generally cannot be added to Library collections. https://www.library.ualberta.ca/aboutus/collection/collection-policy/etextbooks

Yano, B., \& Myers, C. (2019). Stakes and stakeholders: Open Educational Resources-Framing the issues. In A. Wesolek, J. Lashley, \& A. Langley (Eds.), OER: A field guide for academic librarians, editors cut. Pacific University Press. https://boisestate.pressbooks.pub/oer-field-guide/ 


\section{Appendix A}

\section{Open Education Outreach Communications Template}

SUBJECT LINE: Alternatives to required, student-purchased course textbooks

Dear \#\#\#,

COVID-19 is having a dramatic impact on the Library's ability to provide access to its print collections. Although we have implemented a curbside pickup option for books, the requirements regarding quarantine periods for physical items will make our very popular textbook lending program impossible to offer in Fall 2020. Students have relied heavily on the Library's textbook lending program in the past. Since this program's inception, students have gained access to thousands of course readings, resulting in 133,844 checkouts. Without access to this program, and facing increasing financial pressures that may prevent them from purchasing their own textbooks, students may have difficulty acquiring required course materials.

While we will seek to purchase electronic versions of textbooks whenever possible, many textbooks publishers do not sell ebook versions of textbooks to libraries and we cannot purchase an electronic version to lend to students.

Fortunately, there are many options for course materials provided through the Library:

The availability of openly licensed, quality textbooks has increased dramatically in the past five years and UA Library staff can help you identify suitable open textbooks for your courses. You can also modify them to better meet your course needs by adding your own custom examples or problems, or by changing the order of chapters to align with your course delivery.

The Library has an extensive collection of ebooks, online reference sources, and journal articles that can be accessed, free of charge, for all members of the UA community. We can help you locate suitable materials or e-versions of texts we already own.

If we do not currently own an ebook version of a required textbook, we can investigate purchasing an ebook version for our collection.

Please let me know as soon as possible if you would like to explore any of these alternative options for your \#\#faculty / department / courses. 